Delamorclaz Ruiz, Carolina.

Estudiante de doctorado, Universidad de Castilla-La Mancha.

\title{
Evolución del rol de las mujeres en la animación televisiva.
}

\section{Evolution of the role of women in television animation.}

\author{
TIPO DE TRABAJO:
}

Póster.

PALABRAS CLAVE:

Comedia, feminismo, animación, televisión.

KEY WORDS:

Sitcom, feminism, animation, televisión.

RESUMEN.

La animación como medio audiovisual y visibilizador es analizado, en esta ocasión, desde la perspectiva del feminismo. Por ello, se trata de ofrecer aquí una reflexión que permita entender hasta qué punto se han plasmado las distintas problemáticas de género y sexualidad en el ámbito de la animación televisiva, y así comprobar hasta qué punto se han actualizado los roles femeninos y qué series son más transgresoras en este sentido.

\section{ABSTRACT.}

Animation as audiovisual aid and a way to show social issues in television is analyzed, this time, from the perspective of feminism. Therefore, the purpose here is to offer a reflexion about how television animation has developed issues like gender and sexuality in tv, and to prove how far the female roles have been developed over time in television and what shows are more transgressors in this respect.

\section{CONTENIDO.}

Equidad, independencia económica o libertad sexual son algunos conceptos asociados a las problemáticas de la mujer. Conocedora de esta realidad, la animación ha ido configurando nuevos arquetipos femeninos en un intento por que ellas tengan la misma relevancia que los personajes masculinos. Por su parte, se ofrece una reflexión que permita entender hasta qué punto se han plasmado las distintas problemáticas de género y sexualidad en el ámbito de la animación televisiva. Para ello, se tiene en cuenta la inestimable contribución de diversos estudios de género y sexualidad, como los de Judith Butler, Nancy Fraser o Susan Faludi. El motivo de esta elección es que han sido éstas las que han ofrecido la visión más transversal sobre feminismo, además de que todas ellas están ubicadas en un contexto histórico específico (desde la década de 1960 hasta hoy).

El fin es, en este caso, descubrir si se ha visibilizado y normalizado a las mujeres y qué casos han sido los más efectivos. Por ejemplo, cuánto se ha evolucionado desde Los Picapiedra (que representó durante un largo espacio de tiempo a la madre ama de casa de clase media y caucásica) hasta series actuales como Steven Universe u Hora de aventuras y su lucha contra la censura para visibilizar el LGBTI.

De las muchas problemáticas que pueden ser tratadas, la investigación se ciñe a dos grandes bloques: la economía feminista y el LGBTI. La intención es buscar los elementos que permitan visibilizar y empoderar a las minorías y repensar los roles del género. A 
través de un análisis de los personajes femeninos, se identifican arquetipos y estereotipos. Con ello, se pretende entender la evolución de la mujer a través de la animación y comprobar hasta qué punto se han actualizado los roles femeninos y qué series son más transgresoras.

Al comparar series como Los Picapiedra ${ }^{1}$, Los Supersónicos ${ }^{2}$ y Wait Till Your Father Gets Home ${ }^{3}$, siendo todas de la misma productora (Hanna-Barbera) se percibe que hay una evolución respecto a la imagen de la mujer y su papel dentro y fuera de casa. Aparentemente, las tres protagonistas parecen el mismo arquetipo de madre y ama de casa, pero existen algunos matices que las diferencian entre sí. En los casos de Vilma Picapiedra y Ultra Sónico (1960 y 1962 respectivamente), éstas se limitan a asumir su papel, sin llegar a cuestionarse la dependencia económica y soportando en más de una ocasión reproches por lo que sus maridos consideran tendencias consumistas, sin que se tenga en cuenta su labor como madres y gestoras del hogar. En el caso de Irma Boyle, ya en 1972, estas actitudes machistas parecen disminuir, o al menos volverse más sutiles, aunque su marido sigue manifestando algunas maneras sexistas. Para entender mejor el modelo económico en las familias de Hanna Barbera, merece la pena recordar las teorías de Nancy Fraser (teórica especializada en economía y feminismo). Fraser se sirve de los términos "proveedor" y "cuidador" para diferenciar los distintos papeles dentro del núcleo familiar; propone que ambas funciones se conviertan en universales en el hogar, con independencia del género. Vilma y Ultra serían cuidadoras, especialmente Ultra, que, desde una posición económica más privilegiada, es mostrada como una compradora compulsiva, caprichosa y atolondrada sin apenas responsabilidades o muestras de liderazgo 0 creatividad. En cambio, Irma muestra en alguna ocasión querer empoderarse y realizarse profesionalmente. Con la llegada de Los Simpson a finales de los ochenta, se verá en pantalla a Marge Simpson desarrollando multitud de profesiones y manifestándose creativamente, aunque ser madre y esposa seguirá siendo su principal función. Esta situación es reflejo de la tercera ola del feminismo (iniciada en los noventa), en la que se denuncian problemas similares a los de la segunda ola (años sesenta) pero con un nuevo peligro, pues tal y como denuncia la teórica Susan Faludi se extiende en la población una falsa creencia de igualdad.
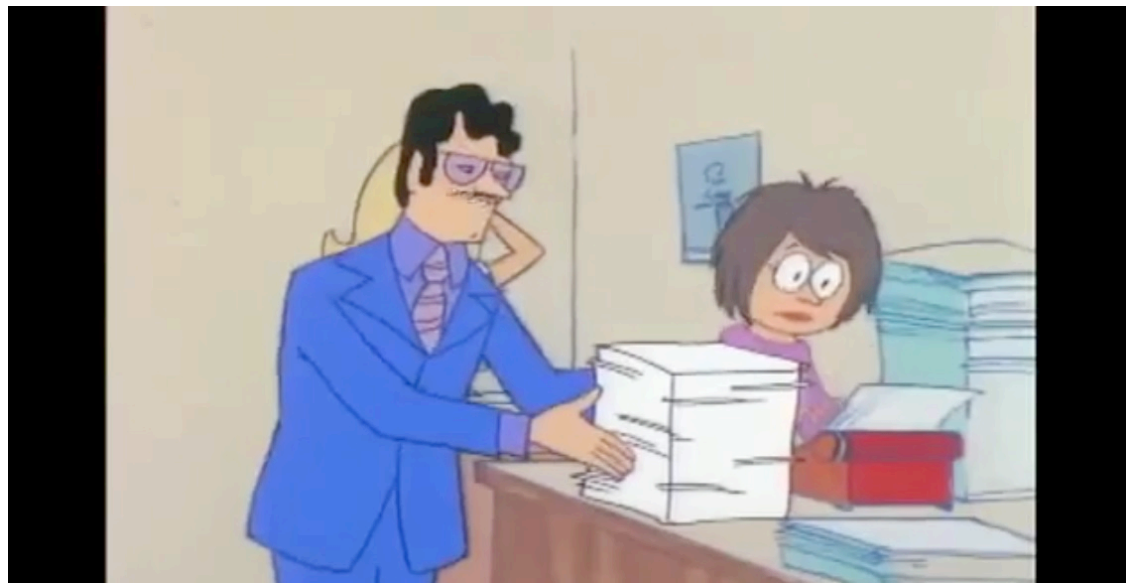

Episodio: Mama's Identity de Wait Till Your Father Gets Home. Director: Peter Luschwitz. Hanna-Barbera, 1972.

En la década de los 2010, se establece una brecha generacional en la animación. La llegada de los directores de la generación milénica no solo rompe con el modelo tradicional de sitcom ${ }^{4}$ de familia caucásica de clase media, sino que se atreve a plasmar nuevas problemáticas, entre ellas la visibilización del colectivo LGBTI. De este modo, si la introducción de personajes homosexuales es ya de por sí complicada y, a menudo es objeto de censura, debe reconocerse el mérito de series como Steven Universe, que ha innovado al incluir personajes de género no binario, así como metáforas que representan la constante transformación del cuerpo. Por ello, hay que destacar aquí el que se incluyan reflexiones como la construcción del cuerpo de Judith Butler.

La animación televisiva debe ser una herramienta que de voz a las problemáticas sociales. Al hacer un análisis global sobre la tendencia en este campo se aprecia que, desde los noventa, este medio se ha vuelto más crítico, pero el fantasma de la censura ha estado presente. Estas series (todas ellas estadounidenses) suelen autocensurarse por miedo a críticas moralistas y el posible rechazo de países compradores potenciales y que persiguen al colectivo LGBTI. Por ello, es necesario que la animación arriesgue para ganar terreno a la censura retrógrada en la televisión, que tiene un espectro muy amplio de edades a las que llegar. Por otra parte, deben

\footnotetext{
${ }_{1}^{1}$ The Flintstones. Creadores: William Hanna, Joseph Barbera. Hanna-Barbera, 1960-1966.

${ }^{2}$ The Jetsons. Creadores: William Hanna, Joseph Barbera. Hanna-Barbera, 1962-1987.

${ }^{3}$ Wait Till Your Father Gets Home, Creadores: William Hanna, Joseph Barbera. Hanna-Barbera, 1972-1974.

${ }^{4}$ Proviene de la contracción en inglés de las Situation Comedy. En castellano se traduce como comedia de situación
} 
sumarse esfuerzos para promover una educación visual y crítica, pues algunas de las series analizadas son falsamente tomadas como feministas.

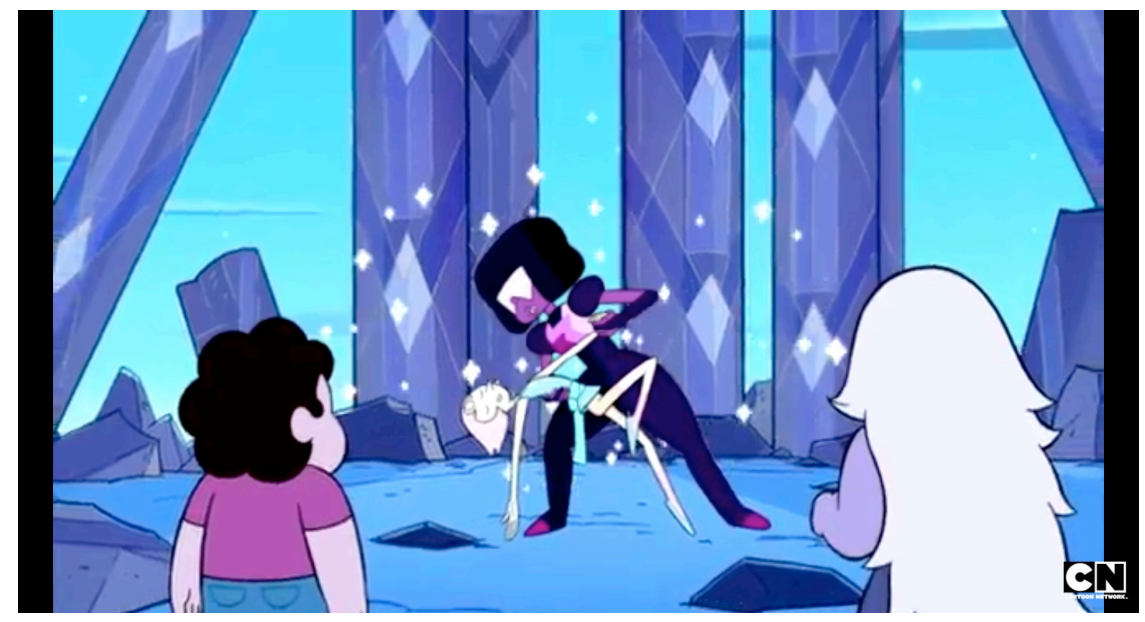

Episodio: Cry For Help de Steven Universe. Directores: Ki-Yong Bae y Jin-Hee Park. Cartoon Network, 2015.

\section{FUENTES REFERENCIALES.}

Butler, Judith. El género en disputa: El feminismo y la subversión de la identidad. Barcelona: Ediciones Paidós Ibérica S.A., 2007. ISBN: 9788449320309.

Faludi, Susan. Reacción. La guerra no declarada contra la mujer moderna. Barcelona: Editorial Angrama. 1993. ISBN: 9788433902061.

Fraser, Nancy. lustitia interrupta. Reflexiones críticas desde la posición postsocialista. Santa Fé de Bogotá: Siglo del Hombre Ed., Universidad de los Andes. 1997. ISBN: 9789586650090. 